\title{
Stratification of Wilms tumor by genetic and epigenetic analysis
}

\author{
Richard H. Scott ${ }^{1}$, Anne Murray ${ }^{1}$, Linda Baskcomb ${ }^{2}$, Clare Turnbull ${ }^{1}$, Chey Loveday ${ }^{1}$, \\ Reem Al-Saadi ${ }^{3}$, Richard Williams ${ }^{3}$, Fin Breatnach ${ }^{4}$, Mary Gerrard ${ }^{5}$, Juliet Hale ${ }^{6}$, \\ Janice Kohler ${ }^{7}$, Pablo Lapunzina ${ }^{8}$, Gill A. Levitt ${ }^{9}$, Sue Picton ${ }^{10}$, Barry Pizer ${ }^{11}$, Milind D. \\ Ronghe $^{12}$, Heidi Traunecker ${ }^{13}$, Denise Williams ${ }^{14}$, Anna Kelsey ${ }^{15}$, Gordan M. Vujanic ${ }^{16}$, \\ Neil J. Sebire ${ }^{17}$, Paul Grundy ${ }^{18}$, Charles A. Stiller ${ }^{19}$, Kathy Pritchard-Jones ${ }^{3,20}$, Jenny \\ Douglas $^{1}$ and Nazneen Rahman ${ }^{1}$ \\ ${ }^{1}$ Division of Genetics \& Epidemiology, Institute of Cancer Research and Royal Marsden Hospital, Sutton, UK \\ ${ }^{2}$ The Wellcome Trust/Cancer Research UK Gurdon Institute, University of Cambridge, Cambridge, UK \\ ${ }^{3}$ Division of Molecular Pathology, Institute of Cancer Research and Royal Marsden Hospital, Sutton, UK \\ 4 Department of Paediatric Oncology, Our Lady's Children's Hospital, Dublin, Ireland \\ ${ }^{5}$ Department of Paediatric Oncology, Sheffield Children's Hospital, Sheffield, UK \\ ${ }^{6}$ Department of Paediatric Oncology, Royal Victoria Infirmary, Newcastle Upon Tyne, UK \\ 7 Department of Paediatric Oncology, Southampton General Hospital, Southampton, UK \\ ${ }^{8}$ Department of Genetics, Hospital Universitario La Paz, Madrid, Spain \\ ${ }^{9}$ Department of Haematology/Oncology, Great Ormond Street Hospital, London, UK \\ ${ }^{10}$ Regional Paediatric Oncology Unit, St James's University Hospital, Leeds, UK \\ ${ }^{11}$ Department of Paediatric Oncology, Alder Hey Children's Hospital, Liverpool, UK \\ 12 Schiehallion Unit, Royal Hospital for Sick Children, Glasgow, UK \\ 13 Department of Paediatric Oncology, Children's Hospital for Wales, Cardiff, UK \\ 14 Department of Paediatric Oncology, Addenbrooke's NHS Trust, Cambridge, UK \\ ${ }^{15}$ Department of Paediatric Pathology, Royal Manchester Children's Hospital, Manchester, UK \\ ${ }^{16}$ Department of Histopathology, School of Medicine, Cardiff University, Cardiff, UK \\ ${ }^{17}$ Department of Histopathology, Great Ormond Street Hospital, London, UK \\ 18 Pediatric Hematology, Stollery Children's Hospital, Edmonton, Canada \\ ${ }^{19}$ Childhood Cancer Research Group, Department of Paediatrics, University of Oxford, Oxford, UK \\ ${ }^{20}$ Molecular Haematology and Cancer Biology Unit, University College London, Institute of Child Health, London, UK \\ Correspondence to: Nazneen Rahman, email: nazneen.rahman@icr.ac.uk \\ Keywords: Wilms tumor, WT1, WTX, CTNNB1, TP53, 11 p15, somatic genetic mutation, epigenetic \\ Received: March 23, 2012, $\quad$ Accepted: March 29, 2012, $\quad$ Published: March 31, 2012
}

Copyright: $\odot$ Scott et al. This is an open-access article distributed under the terms of the Creative Commons Attribution License, which permits unrestricted use, distribution, and reproduction in any medium, provided the original author and source are credited.

\section{ABSTRACT:}

Somatic defects at five loci, WT1, CTNNB1, WTX, TP53 and the imprinted $11 \mathrm{p} 15$ region, are implicated in Wilms tumor, the commonest childhood kidney cancer. In this study we analysed all five loci in 120 Wilms tumors. We identified epigenetic 11p15 abnormalities in 69\% of tumors, 37\% were $\mathrm{H} 19$ epimutations and 32\% were paternal uniparental disomy (pUPD). We identified mutations of WTX in 32\%, CTNNB1 in 15\%, WT1 in 12\% and TP53 in $5 \%$ of tumors. We identified several significant associations: between $11 \mathrm{p} 15$ and $W T X(P=0.007)$, between WT1 and CTNNB1 ( $P<0.001)$, between WT1 and $p U P D 11 \mathrm{p} 15(\mathrm{P}=0.01)$, and a strong negative association between $W T 1$ and $H 19$ epimutation $(P<0.001)$. We next used these data to stratify Wilms tumor into three molecular Groups, based on the status at 11p15 and WT1. Group 1 tumors (63\%) were defined as 11p15-mutant and WT1-normal; a third also had WTX mutations. Group 2 tumors (13\%) were WT1-mutant. They either had 11 p15 pUPD or were 11p15-normal. Almost all had CTNNB1 mutations but none had H19 epimutation. Group 3 tumors $(25 \%)$ were defined as 11 p15-normal and WT1-normal and were typically normal at all five loci $(P<0.001)$. We also identified a novel clinical association between $H 19$ epimutation and bilateral disease $(P<0.001)$. These data provide new insights into the pattern, order, interactions and clinical associations of molecular events in Wilms tumor. 


\section{INTRODUCTION}

Wilms tumor is the commonest childhood kidney cancer and affects 1 in 10,000 children [1]. 5\% of individuals have bilateral tumors affecting both kidneys [2]. Most Wilms tumors occur in otherwise well children. Approximately $5 \%$ of such children have underlying constitutional mutations at $W T 1$ or epigenetic defects at chromosome $11 \mathrm{p} 15$ that predispose to Wilms tumor [3]. Over the past 25 years extensive research has implicated somatic abnormalities at five loci in Wilms tumorigenesis. These are mutations in WT1, CTNNB1,WTX, TP53 and epigenetic 11p15 abnormalities at the imprinted H19/IGF2 locus [4-11].

Despite the considerable number of Wilms tumors that have been collected through international trials [1215], limited systematic molecular profiling of these loci has been performed. A major constraint has been the difficulty in undertaking epigenetic analyses at $11 \mathrm{p} 15$. Two principal somatic abnormalities occur at $11 \mathrm{p} 15$ : paternal uniparental disomy (pUPD 11p15) and H19 epimutation, also known as $I G F 2$ loss of imprinting [9, 10, 16-19]. These defects result in $H 19$ hypermethylation and biallelic $I G F 2$ expression. In addition, somatic copy number defects at $11 \mathrm{p} 15$ such as maternal deletions and paternal duplications are reported in a small number of tumors. Comprehensive $11 \mathrm{p} 15$ analysis to detect these abnormalities has historically required large amounts of

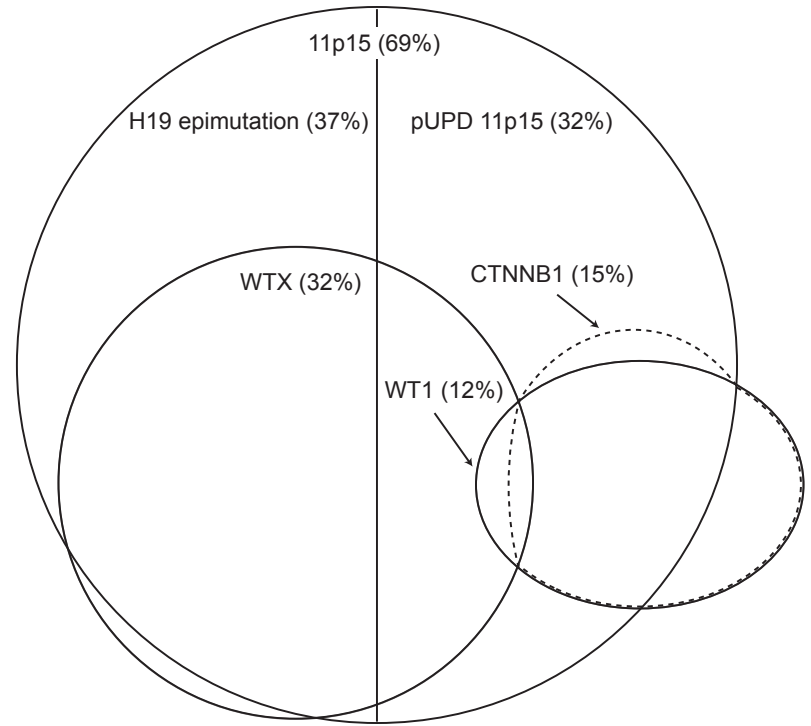

Figure 1: Schematic diagram of the overlapping distributions of molecular abnormalities at 11p15, $W T X, W T 1$ and $C T N N B 1$ in Wilms tumor. The percentage of sporadic tumors with each abnormality in our series is indicated in brackets. CTNNB1 mutations occur predominantly in tumors with WT1 mutations. WTX mutations occur predominantly in tumors with $11 \mathrm{p} 15$ defects. WT1-mutant tumors often have pUPD 11 p15 while $H 19$ epimutation, the other class of $11 \mathrm{p} 15$ defect, is not seen in this context. WTX mutations are infrequent in tumors with $W T 1$ or $C T N N B 1$ mutations. (pUPD: paternal uniparental disomy) tumor sample and multiple, technically demanding assays. Thus, although $11 \mathrm{p} 15$ defects are by far the commonest abnormality in Wilms tumor, disrupted in $50-75 \%$ of tumors, $11 \mathrm{p} 15$ has often not been analysed to completion $[9,10,16-19]$.

To overcome the difficulties of $11 \mathrm{p} 15$ profiling, we previously optimised a MS-MLPA (methylation-specific multiplex ligation-dependent probe amplification) assay of $11 \mathrm{p} 15$ which allows reliable and comprehensive analysis of both epigenetic and copy number defects in a single analysis that is cost and time-efficient and requires only a small amount of DNA [20,21]. In this study we performed 11p15 MS-MLPA together with mutation analyses at $W T 1, C T N N B 1, W T X$ and TP53 in a series of 120 Wilms tumors to yield new insights into the patterns and interactions of molecular events at the five loci in Wilms tumorigenesis. Our series included 100 'sporadic' tumors in which constitutional defects at WT1 and $11 \mathrm{p} 15$ had been excluded and 20 cases with constitutional WT1 or $11 \mathrm{p} 15$ defects. The latter were included to facilitate investigation into the order of somatic events in tumors as, by definition, the constitutional abnormality is the first event in such tumors.

\section{RESULTS}

\section{Frequency of somatic mutations in sporadic tumors}

In the sporadic tumors, the most common somatic abnormality was at $11 \mathrm{p} 15$, which was abnormal in $69 \%$ and was due to $H 19$ epimutation in $37 \%$ and pUPD $11 \mathrm{p} 15$ in $32 \%$. Monoallelic $W T X$ mutations were present in $32 \%$ of sporadic tumors. Twenty-one were whole gene deletions and three were truncating point mutations. As expected, the mutations were hemizygous in males and heterozygous in females. Biallelic WT1 abnormalities were detected in $12 \%$ of sporadic tumors and resulted from either a single WT1 mutation accompanied by UPD for the mutated allele, or two different somatic WT1 mutations. CTNNB1 mutations were present in $15 \%$ and TP53 mutations in 5\% of sporadic tumors. The frequencies of individual somatic abnormalities are similar to those reported in previous studies $[4,7-11,16,17,19,22-29]$. The full results are given in Supplementary Table 1 and a summary of the results in Table 1.

\section{Frequency of mutations in tumors from individuals with constitutional defects}

In tumors from individuals with constitutional WT1 mutation, the wild-type WT1 allele was somatically inactivated in the tumor, either by UPD or by a somatic mutation. Seven of the nine tumors had CTNNB1 
mutations and the remaining two tumors had WTX deletions. In tumors from individuals with constitutional $11 \mathrm{p} 15$ defects there was no additional somatic $11 \mathrm{p} 15$ defect, as expected. Furthermore, no WT1 or CTNNB1 mutations were detected. Three tumors had $W T X$ deletions. The full results are given in Supplementary Table 1 and a summary of the results in Table 1 .

\section{Associations between loci}

We examined the 120 tumors for associations between molecular defects and identified four significant associations between abnormalities at different loci (Figure 1, Supplementary Table 2). Firstly, we identified a strong, novel, positive association between $11 \mathrm{p} 15$ and $W T X$ defects. WTX mutations were significantly more frequent in tumors with $11 \mathrm{p} 15$ defects than those without (25/61 vs $2 / 22, \mathrm{P}=0.007)$, and only two $W T X$-mutant tumors had normal $11 \mathrm{p} 15$ status (Table 1). The two subclasses of $11 \mathrm{p} 15$ defect, H19 epimutation and pUPD $11 \mathrm{p} 15$, were present in similar proportions of $W T X$ mutant tumors (15/25 vs 10/25). We identified significant associations between $11 \mathrm{p} 15$ and WT1 mutations, but in contrast to $W T X$, the associations differed according to the nature of the $11 \mathrm{p} 15$ defect. There was a strong negative association between WT1 mutation and H19 epimutation, which was not found in any WT1-mutant tumor $(0 / 17$ vs $24 / 61 \mathrm{P}<0.001)$ consistent with previous observational data [23]. In contrast there was a positive association between WT1 mutation and pUPD 11p15 which was present in 12/17 WT1-mutant tumors (12/17 vs $21 / 61 \mathrm{P}=0.01)$. Finally, consistent with multiple previous studies, CTNNB1 mutations were significantly more frequent in tumors with $W T 1$ mutations than those without $(15 / 17$ vs $2 / 63, \mathrm{P}<0.001)[26,29,30]$. Each of the three TP53-mutant tumors also had H19 epimutation, but this association did not reach statistical significance.

\section{Molecular stratification of Wilms tumor into three groups}

We examined the patterns of abnormalities at the five loci. This allowed us to partition tumors into molecular groups according to their status at WT1 and $11 \mathrm{p} 15$. The Groups are equally applicable to tumors from sporadic and constitutional cases and both are included in the Group descriptions below. However, it is likely that the relative contributions of the Groups to the sporadic tumors better reflects the pattern in unselected Wilms tumor series (Figure 2, Table 2 and Supplementary Table 1).

Table 1: Results at the five loci in the 120 Wilms tumors.

\begin{tabular}{|c|c|c|c|c|}
\hline & \multicolumn{2}{|c|}{ Sporadic tumors } & \multicolumn{2}{|c|}{ All tumors } \\
\hline & $n^{*}$ & $\%$ & $\mathbf{n}$ & $\%$ \\
\hline Any $11 p 15$ abnormality & $62 / 90$ & $69 \%$ & $81 / 110$ & $74 \%$ \\
\hline - H19 epimutation & 33 & $37 \%$ & 37 & $34 \%$ \\
\hline - pUPD 11p15 & 29 & $32 \%$ & 44 & $40 \%$ \\
\hline WTX mutation & $24 / 74$ & $32 \%$ & $29 / 87$ & $33 \%$ \\
\hline - WTX deletion & 21 & $28 \%$ & 26 & $30 \%$ \\
\hline - Point mutation & 3 & $4 \%$ & 3 & $3 \%$ \\
\hline WT1 mutation ${ }^{\dagger}$ & $8 / 66$ & $12 \%$ & $17 / 80$ & $21 \%$ \\
\hline - Mutation and UPD WT1 & 5 & $8 \%$ & 12 & $15 \%$ \\
\hline - Two different mutations & 3 & $5 \%$ & 5 & $6 \%$ \\
\hline CTNNB1 mutation & $12 / 79$ & $15 \%$ & $19 / 96$ & $20 \%$ \\
\hline TP53 mutation & $3 / 65$ & $5 \%$ & $3 / 76$ & $4 \%$ \\
\hline \multicolumn{5}{|c|}{$\begin{array}{l}\text { *Denominators at each locus are the number of tumors successfully } \\
\text { analysed at that locus. } \\
\text { †Al WT1-mutant tumors had biallelic mutations; this was either one WT1 } \\
\text { mutation followed by UPD or two separate mutations. }\end{array}$} \\
\hline
\end{tabular}




\section{Group 1-11p15-mutant, WT1-normal tumors}

We defined Group 1 tumors as having an 11p15 defect but no WT1 mutation. They were the most common, accounting for $58 \%$ of all tumors and $63 \%$ of sporadic tumors. We divided Group 1 into two subgroups; Group 1A tumors which have $H 19$ epimutations ( $31 \%$ of tumors); and Group 1B, which have pUPD 11p15 (27\% of tumors). $W T X$ mutations were present in $32 \%$ of Group 1 tumors. CTNNB1 mutations were rare, with one CTNNB1 mutation identified in a Group 1A tumor and one in a Group 1B tumor. TP53 mutations were found in three Group 1A tumors.

\section{Group 2 - WT1-mutant, 11p15 pUPD or 11p15-normal tumors}

We defined Group 2 tumors as those with WT1 mutations. Group 2 accounted for $22 \%$ of all tumors and $13 \%$ of sporadic tumors. The tumors either had $11 \mathrm{p} 15$ pUPD (71\%) or were $11 \mathrm{p} 15$-normal (29\%). CTNNB1 mutation was present in $88 \%$. WTX mutations were seen in a smaller proportion (25\%). H19 epimutation was not found in any Group 2 tumor.

\section{Group 3-11p15-normal, WT1-normal tumors}

We defined Group 3 tumors as having no abnormality at $W T 1$ or $11 \mathrm{p} 15$. They accounted for $25 \%$ of sporadic tumors. CTNNB1, WTX and TP53 mutations were not detected in any Group 3 tumor and together were significantly less frequent than in Groups 1 and 2 (0/16 vs $37 / 62, \mathrm{P}<0.001)$. Thus, the Group 3 tumors were polynegative for abnormalities at all five loci.

\section{Clinical associations of molecular groups}

The clinical associations of constitutional defects are well established and we therefore focussed our analyses on evaluating the associations in sporadic tumors, in which constitutional WT1 and $11 \mathrm{p} 15$ defects had been excluded. This revealed two interesting, novel, significant associations with younger age at diagnosis and with bilateral disease (Table 3, Supplementary Table 3). Age at diagnosis was significantly lower in sporadic tumors with somatic WT1 mutations (Group 2), compared with Group 1 and 3 tumors ( 14 months vs 38 months, $\mathrm{P}<0.001$ ). Bilateral disease was significantly more frequent in sporadic tumors with somatic H19 epimutation (Group 1 A tumors), than other groups $(7 / 23$ vs $0 / 41, \mathrm{P}<0.001)$. Furthermore, $H 19$ epimutation was present in three of four additional bilateral cases which could not be classified to a molecular Group because of failed WT1 analysis. Thus, 10 of 11 cases with bilateral tumors without constitutional mutations had somatic H19 epimutation $(\mathrm{P}<0.001)$. In the two individuals where tumor was available from both kidneys the $H 19$ epimutation was present bilaterally.

\section{DISCUSSION}

Our results identify novel molecular associations and in particular clarify the interactions and timing of 11 p15 defects in Wilms tumor. We report a novel, strong association between defects at $11 \mathrm{p} 15$ and WTX mutations; $93 \%$ of $W T X$ mutations occurred in tumors with $11 \mathrm{p} 15$

Table 2: Frequency of abnormalities at the five loci by molecular Group.

\begin{tabular}{|c|c|c|c|c|c|c|c|c|}
\hline & \multicolumn{2}{|c|}{ Group 1A } & \multicolumn{2}{|c|}{ Group 1B } & \multicolumn{2}{|c|}{ Group 2} & \multicolumn{2}{|c|}{ Group 3} \\
\hline & $\mathbf{n}^{*}$ & $\%$ & $\mathbf{n}$ & $\%$ & $\mathbf{n}$ & $\%$ & $\mathbf{n}$ & $\%$ \\
\hline Sporadic tumors & $23 / 64$ & $36 \%$ & $17 / 64$ & $27 \%$ & $8 / 64$ & $13 \%$ & $16 / 64$ & $25 \%$ \\
\hline All tumors & $24 / 78$ & $31 \%$ & $21 / 78$ & $27 \%$ & $17 / 78$ & $22 \%$ & $16 / 78$ & $21 \%$ \\
\hline Any $11 p 15$ abnormality & $24 / 24$ & $100 \%$ & $21 / 21$ & $100 \%$ & $12 / 17$ & $71 \%$ & $0 / 16$ & $0 \%$ \\
\hline - H19 epimutation & $24 / 24$ & $100 \%$ & $0 / 21$ & $0 \%$ & $0 / 17$ & $0 \%$ & $0 / 16$ & $0 \%$ \\
\hline - pUPD 11p15 & $0 / 24$ & $0 \%$ & $21 / 21$ & $100 \%$ & $12 / 17$ & $71 \%$ & $0 / 16$ & $0 \%$ \\
\hline WTX mutation & $10 / 23$ & $43 \%$ & $4 / 21$ & $19 \%$ & $3 / 12$ & $25 \%$ & $0 / 16$ & $0 \%$ \\
\hline WT1 mutation & $0 / 24$ & $0 \%$ & $0 / 21$ & $0 \%$ & $17 / 17$ & $100 \%$ & $0 / 16$ & $0 \%$ \\
\hline CTNNB1 mutation & $1 / 24$ & $4 \%$ & $1 / 21$ & $5 \%$ & $15 / 17$ & $88 \%$ & $0 / 16$ & $0 \%$ \\
\hline TP53 mutation & $3 / 22$ & $14 \%$ & $0 / 21$ & $0 \%$ & $0 / 11$ & $0 \%$ & $0 / 16$ & $0 \%$ \\
\hline
\end{tabular}


defects. Most importantly, we demonstrate that epigenetic $11 \mathrm{p} 15$ defects occur in different contexts and in (at least) two distinct types of Wilms tumor that we call Group 1 and Group 2 tumors. In Group 1 tumors, which are the most common molecular subtype, both classes of $11 \mathrm{p} 15$ defect occur. It is probable that in Group 1 tumors the $11 \mathrm{p} 15$ defect is an initiating / early event that precedes WTX mutation. This is suggested by the occurrence of $W T X$ mutation in the tumors with constitutional 11p15 defects, in which it must be a secondary event, and also by the report of individuals with constitutional $W T X$ mutations who have a skeletal dysplasia but do not develop Wilms tumor [31].

By contrast, in Group 2 tumors 11p15 defects are secondary rather than initiating events, and only one class of defect, pUPD 11p15, occurs; H19 epimutation occurs very rarely, if at all. In Group 2 tumors, WT1 mutation appears to be the initiating / early event (Figure 2). Following WT1 mutation, a single somatic recombination event causing pUPD encompassing both WT1 and 11 p15 then occurs in a substantial proportion. This will simultaneously inactivate the second WT1 allele and cause $H 19$ hypermethylation and biallelic $I G F 2$ expression. The tumor data from individuals with constitutional defects strongly supports this sequence as eight of nine tumors from individuals with constitutional WT1 mutations had somatic pUPD 11p15, whereas none of 11 individuals with constitutional $11 \mathrm{p} 15$ defects had somatic WT1 mutations.

A notable observation that emerged from these analyses is that Group 3 tumors, which are defined as those with normal status at both $W T 1$ and $11 \mathrm{p} 15$, were typically also negative for mutations at WTX, CTNNB1 and TP53 $(\mathrm{P}<0.001$, Table 2$)$. In our series this poly-negative group accounts for $\sim 25 \%$ of tumors. The underlying molecular abnormalities in these tumors are currently unknown and research focussed on Group 3 tumors may be particularly fruitful in the discovery of further Wilms tumor genes.

We detected two novel, significant, clinical associations, primarily because we exhaustively discriminated tumors with constitutional $11 \mathrm{p} 15$ and WT1 defects from sporadic tumors. This has rarely been undertaken systematically in previous molecular analyses of Wilms tumors. The first significant association was between sporadic bilateral disease and sporadic Group 1 A tumors; 10 of 11 cases with sporadic bilateral tumors had somatic $H 19$ epimutation $(\mathrm{P}<0.001)$. A possible explanation is that the $11 \mathrm{p} 15$ defects that drive these tumors occur as early post-zygotic events, and can thus be present in both kidneys but absent from lymphocytes. This may represent a form of tissue-specific cancer predisposition that is intermediate between classic constitutional cancer predisposition and tumor-restricted,
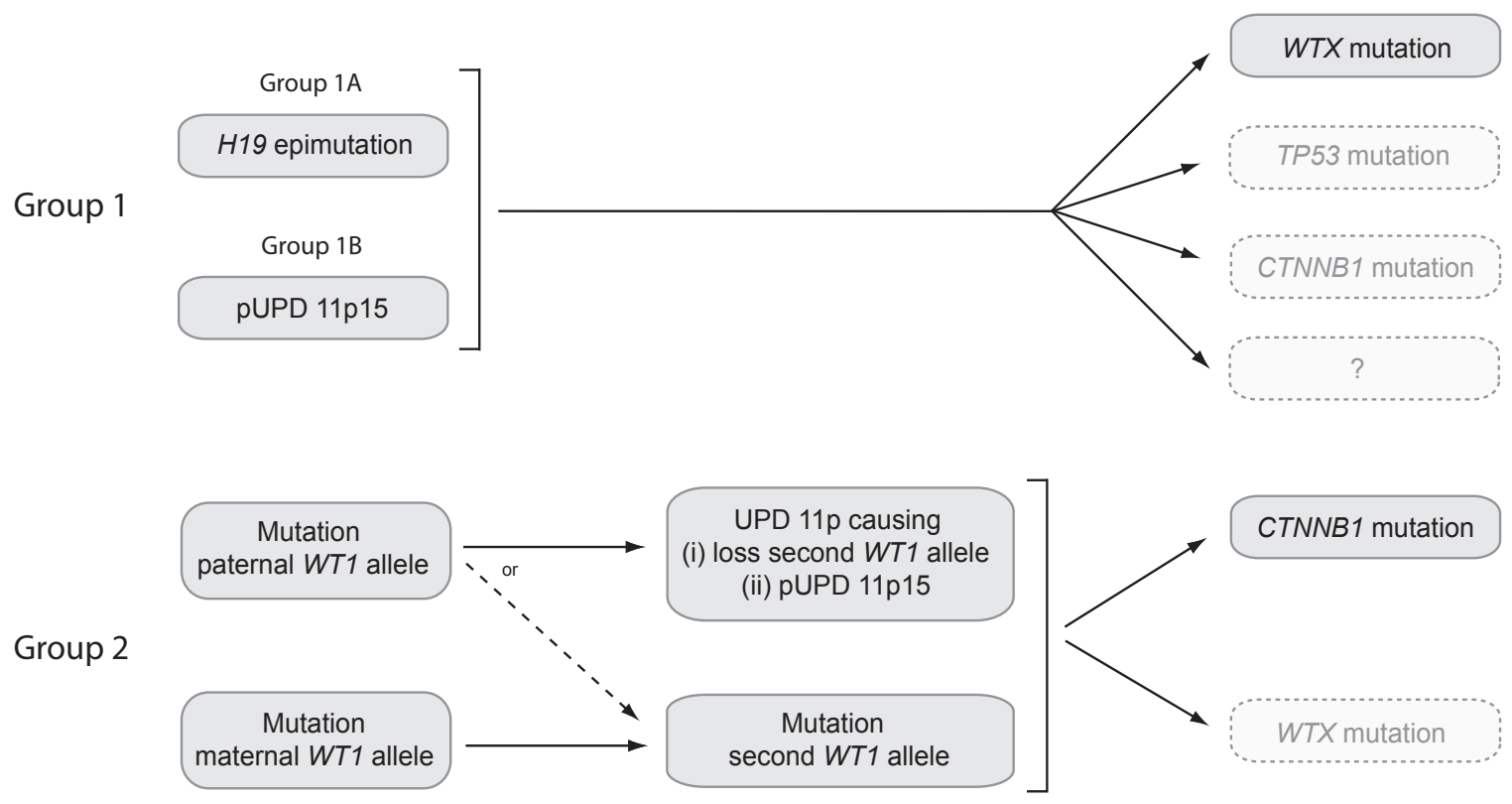

Figure 2: Schematic diagram of the molecular events in tumors in Group 1 and Group 2. Group 1 tumors are defined as having 11p15 defects in the absence of a WT1 mutation. Group 1 is subdivided into Group 1A, with H19 epimutation, and Group 1B, with pUPD 11p15. In Group 1 tumors, an $11 \mathrm{p} 15$ defect occurs as the likely first event, occurring either constitutionally or somatically. Approximately $30 \%$ of Group 1 tumors undergo WTX mutation, while mutations in TP53 and CTNNB1 mutation are infrequent. No additional event is currently identifiable in the majority of Group 1 tumors. Group 2 tumors are defined as having WT1 mutations. In Group 2 tumors, monoallelic WT1 mutation is the likely first event, occurring either constitutionally or somatically. Group 2 tumors in which the mutation targets the paternally-derived $W T 1$ allele frequently next undergo somatic recombination resulting in UPD 11p and causing loss of the wild-type WT1 allele and pUPD 11p15. The remainder undergo mutation or deletion of the wild-type WT1 allele and retain normal $11 \mathrm{p} 15$ status. The large majority ( 90\%) of Group 2 tumors undergo CTNNB1 mutation, while WTX mutation is less common. (pUPD: paternal uniparental disomy; UPD: uniparental disomy) 
somatic events. If so, it may have relevance to other bilateral / multifocal cancers. It is noteworthy that the association with sporadic bilateral tumors was restricted to $H 19$ epimutation and did not extend to pUPD $11 \mathrm{p} 15$. This may indicate that either the risk of Wilms tumor is higher in $H 19$ epimutation than in pUPD 11 p15 tumors and/or that $H 19$ epimutation is more likely to occur earlier in embryogenesis and hence be present in both kidneys.

The second clinical association that emerged from our data is between early age of diagnosis and sporadic Group 2 tumors, i.e. tumors with somatic but not constitutional WT1 mutations. It is well established that most constitutional cancer syndrome mutations, including $W T 1$, are associated with younger age of onset. However, this association is generally believed to be restricted to tumors with constitutional mutations, rather than their somatically driven counterparts. This may not be the case for Wilms tumors with WT1 mutations, as our analyses demonstrate that the median age of onset in children with somatic WT1 mutations was 14 months. This is significantly lower than the other groups, and the median age of sporadic Wilms tumor (38 months) and is similar to tumors in children with constitutional WT1 mutations [3, 32-34]. The biological explanation for this association is obscure, but it may indicate that WT1 mutations are associated with a more rapid progression to Wilms tumor than other molecular abnormalities.

In summary, through analysis of a series of Wilms tumors for molecular defects at the five known Wilms tumor genetic loci, this study provides new insights into the sequence and patterns of events that occur during
Wilms tumorigenesis. Similar stratification of tumors in large, ongoing clinical trials will allow evaluation of these associations in larger numbers with richer clinicpathological data, and will likely result in further advances in our understanding of the molecular processes that result in Wilms tumor and their clinical manifestations.

\section{METHODS}

\section{Samples}

We included 120 individuals affected with Wilms tumor recruited by the Wilms Tumor Susceptibility Collaboration (WTSC) as part of the Factors Associated with Childhood Tumors (FACT) study. The collaborators in the WTSC are given in the Supplementary Note. The series consisted of 100 sporadic tumors from children with non-syndromic Wilms tumor from the UK in whom constitutional predisposing defects at WT1 and 11p15 had been excluded, 9 tumors from individuals with constitutional WT1 mutations and 11 from individuals with constitutional 11p15 defects (Supplementary Table 1). Patients and/or their families gave consent for the research, which has multicenter research ethics approval (MREC05/02/17).

From each case, genomic DNA was extracted from tumor and peripheral blood lymphocytes using standard techniques. Tumor samples were supplied by the recruiting centre for DNA extraction either as fresh frozen or paraffin

Table 3: Frequency of bilateral disease and median age at diagnosis of sporadic tumors in the three molecular Groups.

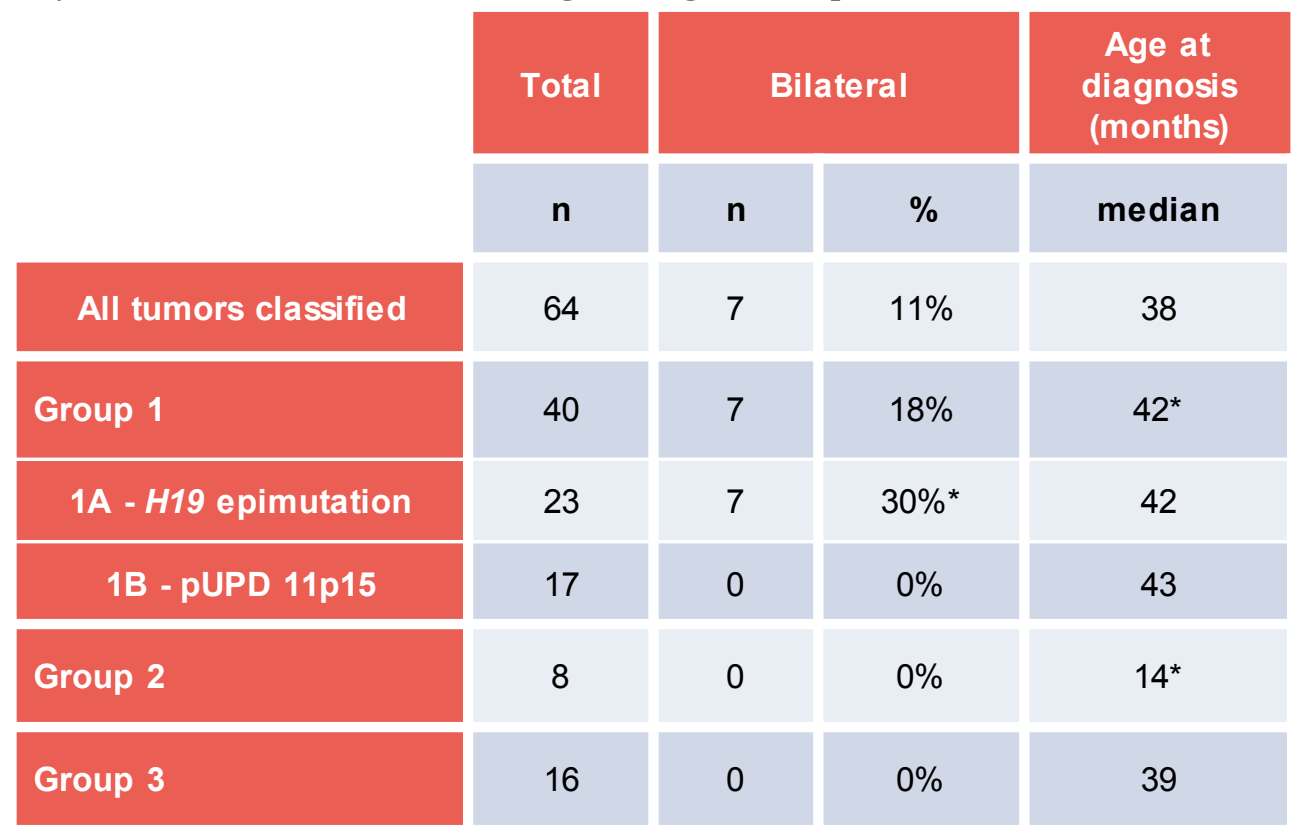

*Statistically significant associations. $P$ values are given in the text. pUPD: paternal uniparental disomy. 
embedded tumor. In all cases, a histological section corresponding to the extracted specimen was reviewed by a single pathologist. Cases were included in the study only if this review confirmed the section to be Wilms tumor and that $>80 \%$ examined nuclei were tumor. The large majority of individuals in the series, including all of those with sporadic, non-syndromic disease were treated according to European protocols, in UK Paediatric Oncology centres. In these cases, tumor resection therefore followed neoadjuvant chemotherapy (Supplementary Table 3). Staging and histological group of tumors was classified according to the relevant trial protocol [14, 35-37].

\section{Mutation analysis of $W T 1, T P 53, C T N N B 1$ and WTX}

We analysed WT1, TP53 and WTX by direct sequencing of their full coding sequences and intron-exon boundaries in 10, seven and 11 fragments respectively. We analysed the mutation hot-spot of CTNNB1 by sequencing of exon 3 as a single fragment. PCR amplification was performed on native or whole-genome amplified DNA using the primers and conditions specified in Supplementary Table 4. Amplicons were then sequenced using the BigDyeTerminator Cycle Sequencing Kit and an ABI 3730 automated sequencer (Applied Biosystems). Mutations in whole-genome amplified samples were confirmed in native DNA. Sequence traces were analysed using Mutation Surveyor software v3.20 (SoftGenetics) and by visual inspection. Only samples in which $>90 \%$ of the coding sequence of a gene was successfully screened were considered to have passed at that locus. We also performed dosage analysis at WT1 and WTX by MLPA (multiplex ligation-dependent probe amplification) according to the manufacturer's instructions using a customised version of the P118 WT1 kit (MRC Holland) and an ABI 3130 automated sequencer. The P118 kit contains 11 probes targeting the 10 exons of $W T 1$ and 13 probes to flanking genes at $11 \mathrm{p} 13$. To allow dosage analysis at $W T X$, we customised the kit by adding four synthetic probes targeting the WTX coding sequence, two probes targeting the $\mathrm{X}$ chromosome outside the WTX deletion region and one $\mathrm{Y}$ chromosome probe (Supplementary Table 5). MLPA traces were analysed using GeneMarker v1.51 software (SoftGenetics). For WT1 and WTX, samples were required to pass MLPA analysis to pass analysis overall at the locus.

\section{Epigenetic analysis of 11 p15}

We analysed the imprinted 11 p15 region for the range of reported methylation and copy number defects using methylation-specific MLPA (MS-MLPA) as previously described using a customised version of the ME030 kit (MRC Holland) [20, 21]. The assay determines the level of methylation at two differentially methylated regions (DMRs) at 11p15, H19 and KvDMR and also copy number at 28 loci across the 11 p15 region. Samples were classified as follows: (1) Normal methylation and normal copy number - No 11p15 defect, (2) Abnormal methylation and normal copy number - $11 \mathrm{p} 15$ epigenetic defect, subclassified according to pattern of abnormal methylation such that samples with $H 19$ hypermethylation and KvDMR normal methylation were classified as H19 epimutation whilst those with $H 19$ hypermethylation and KvDMR hypomethylation were classified as pUPD 11p15. (3) Abnormal methylation and abnormal copy number - 11p15 copy number defect, deletion (decreased copy number) or duplication (increased copy number); the parent of origin of the abnormal allele is given by the pattern of methylation.

Normal ranges for methylation indices in constitutional samples are as previously published $[20,21]$. To account for the clonal nature of tumor DNA, we used more stringent cut-offs for abnormal methylation, requiring abnormal tumor samples to show $>70 \%$ methylated alleles. In samples with pUPD $11 \mathrm{p} 15$, we confirmed the abnormality by analysis of 11 p15 microsatellites as previously described [20, 21]. Lymphocyte DNA from the proband and available parents was analysed in parallel with tumor DNA, allowing the parental origin of alleles to be assigned.

Where an abnormality was identified in tumor DNA, we analysed lymphocyte DNA for the same abnormality to differentiate constitutional from somatic events. For abnormalities identified in a tumor from individuals with bilateral disease, we analysed DNA from the contralateral tumor if material was available.

\section{Statistical analysis}

We performed comparisons of the frequencies of abnormalities at different loci and between molecular subgroups using a two-sided Fisher's exact test. We compared the frequencies of bilateral disease and unfavorable histology using a two-sided Fisher's exact test and compared stage and age at diagnosis using the Wilcoxon rank-sum test.

\section{ACKNOWLEDGMENTS}

We thank the affected individuals and families involved in the research and the physicians, pathologists and nurses who referred families and provided samples. We thank N. Huxter for coordinating recruitment and B. Ebbs for DNA extraction. We thank N. Coleman, M. Malone, B. Messahel, M. O’Sullivan, R. Nash, S. Popov and L. Price for providing tumor specimens and clinical / histological information. We thank R. Bowman, M. O'Sullivan, I. Slade, M. Stratton, B. Uttenthal for their 
comments on the manuscript. We thank A. Strydom and E. Perdeaux for administrative assistance. The research was carried out as part of the Factors Associated with Childhood Tumors (FACT) study, which is UK Children's Cancer and Leukaemia Group (CCLG) study. The Childhood Cancer Research Group receives funding from the Department of Health and the Scottish Ministers. The views expressed in this publication are those of the authors and not necessarily those of the Department of Health and the Scottish Ministers. R.H.S. was supported by the Michael and Betty Kadoorie Cancer Genetics Research Programme. We acknowledge NHS funding to the NIHR Biomedical Research Centre. This work was supported by grants from Cancer Research UK, and the Institute of Cancer Research (UK). The authors have no conflicts of interests to declare.

\section{REFERENCES}

1. Stiller CA, Parkin DM. International variations in the incidence of childhood renal tumours. Br J Cancer. 1990; 62:1026-1030.

2. Breslow NE, Olson J, Moksness J, Beckwith JB, Grundy P. Familial Wilms' tumor: a descriptive study. Med Pediatr Oncol. 1996; 27:398-403.

3. Scott RH, Stiller CA, Walker L, Rahman N. Syndromes and constitutional chromosomal abnormalities associated with Wilms tumour. J Med Genet. 2006; 43:705-715.

4. Bardeesy N, Falkoff D, Petruzzi MJ, Nowak N, Zabel B, Adam M, Aguiar MC, Grundy P, Shows T, Pelletier J. Anaplastic Wilms' tumour, a subtype displaying poor prognosis, harbours p53 gene mutations. Nat Genet. 1994; 7:91-97.

5. Call KM, Glaser T, Ito CY, Buckler AJ, Pelletier J, Haber DA, Rose EA, Kral A, Yeger H, Lewis WH, et al. Isolation and characterization of a zinc finger polypeptide gene at the human chromosome 11 Wilms' tumor locus. Cell. 1990; 60:509-520.

6. Gessler M, Poustka A, Cavenee W, Neve RL, Orkin SH, Bruns GA. Homozygous deletion in Wilms tumours of a zinc-finger gene identified by chromosome jumping. Nature. 1990; 343:774-778.

7. Koesters R, Ridder R, Kopp-Schneider A, Betts D, Adams V, Niggli F, Briner J, von Knebel Doeberitz M. Mutational activation of the beta-catenin proto-oncogene is a common event in the development of Wilms' tumors. Cancer Res. 1999; 59:3880-3882.

8. Malkin D, Sexsmith E, Yeger H, Williams BR, Coppes MJ. Mutations of the p53 tumor suppressor gene occur infrequently in Wilms' tumor. Cancer Res. 1994; 54:20772079.

9. Ogawa O, Eccles MR, Szeto J, McNoe LA, Yun K, Maw MA, Smith PJ, Reeve AE. Relaxation of insulin-like growth factor II gene imprinting implicated in Wilms' tumour. Nature. 1993; 362:749-751.
10. Rainier S, Johnson LA, Dobry CJ, Ping AJ, Grundy PE, Feinberg AP. Relaxation of imprinted genes in human cancer. Nature. 1993; 362:747-749.

11. Rivera MN, Kim WJ, Wells J, Driscoll DR, Brannigan BW, Han M, Kim JC, Feinberg AP, Gerald WL, Vargas SO, Chin L, Iafrate AJ, Bell DW, Haber DA. An X chromosome gene, WTX, is commonly inactivated in Wilms tumor. Science. 2007; 315:642-645.

12. Green DM, Breslow NE, Beckwith JB, Finklestein JZ, Grundy P, Thomas PR, Kim T, Shochat S, Haase G, Ritchey M, Kelalis P, D'Angio GJ. Effect of duration of treatment on treatment outcome and cost of treatment for Wilms' tumor: a report from the National Wilms' Tumor Study Group. J Clin Oncol. 1998; 16:3744-3751.

13. Grundy PE, Breslow NE, Li S, Perlman E, Beckwith JB, Ritchey ML, Shamberger RC, Haase GM, D’Angio GJ, Donaldson M, Coppes MJ, Malogolowkin M, Shearer P, Thomas PR, Macklis R, Tomlinson G et al. Loss of heterozygosity for chromosomes $1 p$ and $16 q$ is an adverse prognostic factor in favorable-histology Wilms tumor: a report from the National Wilms Tumor Study Group. J Clin Oncol. 2005; 23:7312-7321.

14. Mitchell C, Pritchard-Jones K, Shannon R, Hutton C, Stevens S, Machin D, Imeson J, Kelsey A, Vujanic GM, Gornall P, Walker J, Taylor R, Sartori P, Hale J, Levitt $\mathrm{G}$, Messahel B et al. Immediate nephrectomy versus preoperative chemotherapy in the management of nonmetastatic Wilms' tumour: results of a randomised trial (UKW3) by the UK Children's Cancer Study Group. Eur J Cancer. 2006; 42:2554-2562.

15. Pritchard-Jones K, Pritchard J. Success of clinical trials in childhood Wilms' tumour around the world. Lancet. 2004; 364:1468-1470.

16. Moulton T, Chung WY, Yuan L, Hensle T, Waber P, Nisen P, Tycko B. Genomic imprinting and Wilms' tumor. Med Pediatr Oncol. 1996; 27:476-483.

17. Moulton T, Crenshaw T, Hao Y, Moosikasuwan J, Lin N, Dembitzer F, Hensle T, Weiss L, McMorrow L, Loew T, et al. Epigenetic lesions at the H19 locus in Wilms' tumour patients. Nat Genet. 1994; 7:440-447.

18. Okamoto K, Morison IM, Taniguchi T, Reeve AE. Epigenetic changes at the insulin-like growth factor II/ H19 locus in developing kidney is an early event in Wilms tumorigenesis. Proc Natl Acad Sci U S A. 1997; 94:53675371.

19. Steenman MJ, Rainier S, Dobry CJ, Grundy P, Horon IL, Feinberg AP. Loss of imprinting of IGF2 is linked to reduced expression and abnormal methylation of $\mathrm{H} 19$ in Wilms' tumour. Nat Genet. 1994; 7:433-439.

20. Scott RH, Douglas J, Baskcomb L, Huxter N, Barker K, Hanks S, Craft A, Gerrard M, Kohler JA, Levitt GA, Picton S, Pizer B, Ronghe MD, Williams D, Cook JA, Pujol P et al. Constitutional 11p15 abnormalities, including heritable imprinting center mutations, cause nonsyndromic Wilms tumor. Nat Genet. 2008; 40:1329-1334. 
21. Scott RH, Douglas J, Baskcomb L, Nygren AO, Birch JM, Cole TR, Cormier-Daire V, Eastwood DM, GarciaMinaur S, Lupunzina P, Tatton-Brown K, Bliek J, Maher ER, Rahman N. Methylation-specific multiplex ligationdependent probe amplification (MS-MLPA) robustly detects and distinguishes $11 \mathrm{p} 15$ abnormalities associated with overgrowth and growth retardation. J Med Genet. 2008; 45:106-113.

22. Forbes S, Clements J, Dawson E, Bamford S, Webb T, Dogan A, Flanagan A, Teague J, Wooster R, Futreal PA, Stratton MR. COSMIC 2005. Br J Cancer. 2006; 94:318322.

23. Fukuzawa R, Anaka MR, Weeks RJ, Morison IM, Reeve AE. Canonical WNT signalling determines lineage specificity in Wilms tumour. Oncogene. 2009; 28:10631075.

24. Fukuzawa R, Breslow NE, Morison IM, Dwyer P, Kusafuka T, Kobayashi Y, Becroft DM, Beckwith JB, Perlman EJ, Reeve AE. Epigenetic differences between Wilms' tumours in white and east-Asian children. Lancet. 2004; 363:446451.

25. Gessler M, Konig A, Arden K, Grundy P, Orkin S, Sallan S, Peters C, Ruyle S, Mandell J, Li F, et al. Infrequent mutation of the WT1 gene in 77 Wilms' Tumors. Hum Mutat. 1994; 3:212-222.

26. Maiti S, Alam R, Amos CI, Huff V. Frequent association of beta-catenin and WT1 mutations in Wilms tumors. Cancer Res. 2000; 60:6288-6292.

27. Ruteshouser EC, Robinson SM, Huff V. Wilms tumor genetics: mutations in WT1, WTX, and CTNNB1 account for only about one-third of tumors. Genes Chromosomes Cancer. 2008; 47:461-470.

28. Satoh Y, Nakadate H, Nakagawachi T, Higashimoto K, Joh K, Masaki Z, Uozumi J, Kaneko Y, Mukai T, Soejima $\mathrm{H}$. Genetic and epigenetic alterations on the short arm of chromosome 11 are involved in a majority of sporadic Wilms' tumours. Br J Cancer. 2006; 95:541-547.

29. Wegert J, Wittmann S, Leuschner I, Geissinger E, Graf N, Gessler M. WTX inactivation is a frequent, but late event in Wilms tumors without apparent clinical impact. Genes Chromosomes Cancer. 2009; 48:1102-1111.

30. Fukuzawa R, Heathcott RW, Sano M, Morison IM, Yun K, Reeve AE. Myogenesis in Wilms' tumors is associated with mutations of the WT1 gene and activation of Bcl-2 and the Wnt signaling pathway. Pediatr Dev Pathol. 2004; 7:125137.

31. Jenkins ZA, van Kogelenberg M, Morgan T, Jeffs A, Fukuzawa R, Pearl E, Thaller C, Hing AV, Porteous ME, Garcia-Minaur S, Bohring A, Lacombe D, Stewart F, Fiskerstrand T, Bindoff L, Berland S et al. Germline mutations in WTX cause a sclerosing skeletal dysplasia but do not predispose to tumorigenesis. Nat Genet. 2009; 41:95100 .

32. Breslow N, Olshan A, Beckwith JB, Green DM.
Epidemiology of Wilms tumor. Med Pediatr Oncol. 1993; 21:172-181.

33. Breslow NE, Norris R, Norkool PA, Kang T, Beckwith JB, Perlman EJ, Ritchey ML, Green DM, Nichols KE. Characteristics and outcomes of children with the Wilms tumor-Aniridia syndrome: a report from the National Wilms Tumor Study Group. J Clin Oncol. 2003; 21:4579-4585.

34. Royer-Pokora B, Beier M, Henzler M, Alam R, Schumacher V, Weirich A, Huff V. Twenty-four new cases of WT1 germline mutations and review of the literature: genotype/ phenotype correlations for Wilms tumor development. Am J Med Genet A. 2004; 127A:249-257.

35. Mitchell C, Jones PM, Kelsey A, Vujanic GM, Marsden B, Shannon R, Gornall P, Owens C, Taylor R, Imeson J, Middleton H, Pritchard J. The treatment of Wilms' tumour: results of the United Kingdom Children's cancer study group (UKCCSG) second Wilms' tumour study. Br J Cancer. 2000; 83:602-608.

36. Pritchard J, Imeson J, Barnes J, Cotterill S, Gough D, Marsden HB, Morris-Jones P, Pearson D. Results of the United Kingdom Children's Cancer Study Group first Wilms' Tumor Study. J Clin Oncol. 1995; 13:124-133.

37. Vujanic GM, Sandstedt B, Harms D, Kelsey A, Leuschner I, de Kraker J. Revised International Society of Paediatric Oncology (SIOP) working classification of renal tumors of childhood. Med Pediatr Oncol. 2002; 38:79-82. 